\title{
Un invitado inesperado en nuestras vidas: COVID-19 en Chile
}

\author{
An unwanted guest in our lives: COVID-19 in Chile
}

Menos de 15 días transcurrieron desde la identificación del primer caso de un nuevo cuadro infeccioso severo pulmonar (8 diciembre de 2019, Wuhan, provincia de Hubei, China) hasta la identificación y comunicación al mundo por autoridades chinas del agente causal involucrado ${ }^{1,2}$. Un nuevo agente infeccioso, de la familia de los coronavirus, con capacidad de infectar animales y seres humanos y producir enfermedades zoonóticas, circulando libremente en poblaciones sin experiencia de exposición previa y en circunstancias de amplia movilidad de personas por las bondades del transporte local e internacional ${ }^{3}$.

Previamente, agentes virales de la misma familia, circularon por el mundo ocasionando cuadros respiratorios leves algunos de estos agentes, y cuadros de mayor severidad, como los producidos por virus SARS-CoV (2002, Sindrome Respiratorio Agudo Grave) y por el MERS-CoV (2012, Sindrome Respiratorio del Cercano Oriente), despertando ambos episodios alerta mundial por su capacidad de propagación e importante letalidad ${ }^{4}$. Los primeros reportes sobre las características clínicas y epidemiológicas de la nueva enfermedad, COVID-19, producida por el ahora denominado agente causal SARS-CoV-2 mostraron su rápida y eficiente capacidad de diseminación en la población ${ }^{5}$.

A la fecha de elaboración de este editorial, han transcurrido 122 días desde que la Organización Mundial de la Salud (OMS) declarara situación de Pandemia y alerta sanitaria mundial (30 de enero, 2020). Un total de 218 países y territorios han sido afectados, con 5.817 .385 casos reportados y 362.705 muertes ocurridas ${ }^{6}$.

Transcurridos 89 días desde la confirmación del primer caso en Chile (3 de marzo, 2019), Chile reporta 99.688 casos y 1.054 personas fallecidas a causa de COVID-19. 1.174 pacientes se encuentran en condición clínica crítica, con casos originados desde todas las 15 regiones del país ${ }^{7}$.

La situación experimentada en nuestro país pone en evidencia la recurrencia de situaciones previamente ocurridas en el contexto de enfermedades epidémicas, las que resultan oportuno de revisar. Entre ellas pueden identificarse circunstancias que permiten comprender con mayor amplitud la compleja situación que nuestro país enfrenta e identificar acciones y desafios de una etapa post-pandemia que es preciso recoger.

La dura experiencia de la epidemia del año 1918 (la denominada gripe o influenza española) encontró a nuestro país con algunas enseñanzas derivadas de episodios similares acaecidos en epidemias ocurridas y documentadas a fines del siglo XIX. Entre ellas, la relevancia de los factores sociales y de las condiciones de vida de las comunidades, condiciones gravitantes en la forma en que estas comunidades se ven afectadas al vivir en situaciones desventajosas. También fue debidamente registrada la necesidad de organizar los recursos sanitarios del país de una forma armónica y ordenada. De esta forma, Chile contó con su primer código sanitario precisamente el mismo año (1918) en que ocurre la pandemia mundial de la gripe española ${ }^{8}$. La pandemia llegó rápidamente al continente y a Chile, afectando en sus inicios, principalmente a las clases acomodadas, tal cual ocurrió en la epidemia de 1891. Posteriormente, se difundió ampliamente a la comunidad causando gran mortalidad. 
Gran controversia se suscitó respecto de la mortalidad derivada de la epidemia, observándose el efecto hasta el año 1921 un exceso de mortalidad, en el cual participó, coincidentemente, una segunda epidemia: el tifus exantemático. La enfermedad se apropió de lugares de alta concentración de personas, representados por los cites y conventillos; creció un sentimiento de desconfianza por parte de la ciudadanía hacia la capacidad de respuesta del Estado, representado principalmente por los profesionales médicos. Los efectos de la segunda y tercera ola pandémica fueron mayores que la primera y prolongaron esta epidemia por un período cercano a los tres años ${ }^{9,10}$ (Figura 1).

Circunstancias muy similares, 102 años después de la pandemia señalada, son las que se reproducen en la actual epidemia COVID-19 en nuestro país. La inminencia de nuevas amenazas epidémicas es sistemáticamente comunicada por la OMS y por la comunidad cientifica mundial ${ }^{11}$, para lo cual se disponen de sistemas de vigilancia epidemiológica de carácter global y compromisos contenidos en el Reglamento Sanitario Internacional ${ }^{12}$. Sin embargo, llama la atención la fragilidad global de los sistemas de salud con la cual enfrentan estas amenazas, poniéndolos en tensión extrema, mayormente en países de bajo desarrollo, pero también aquellos de mediano y alto desarrollo económico ${ }^{13}$.

COVID-19 se presenta con mayores tasas de ataque en adultos jóvenes, concentrando su mayor letalidad en adultos mayores y en personas con comorbilidades crónicas, independiente de su edad. Se ha presentado con mayor frecuencia $(5,8 \%)$ en población menor de 15 años respecto de lo reportado por otros países, afortunadamente, con escasas hospitalizaciones y muertes ${ }^{14}$.

Aunque se estima que la enfermedad confiere inmunidad protectora, ello no es aún del todo cierto por el breve tiempo de observación de cohortes afectadas desde el inicio de esta pandemia. El diagnóstico de COVID-19 requiere de la utilización de pruebas diagnósticas de cierta complejidad tecnológica (RT-PCR), cuya interpretación ha resultado controvertida, en especial respecto del carácter contagiante de su resultado positivo persistente más allá de 14-21 días ${ }^{15,16}$. A diferencia de la pandemia por virus H1N1, aún no se dispone de medicamentos antivirales adecuados ni agentes terapéuticos eficaces para combatirla. Aun cuando la frecuencia de formas graves de enfermedad es relativamente baja, la alta contagiosidad del SARS-CoV-2 (Índice de reproducción Ro fluctuante entre 1,4 a 6,4, con promedio de 3,28 y 2,79 de mediana) deriva en un alto número absoluto de pacientes requiriendo potencialmente atención especializada y tecnología de soporte ventilatorio ${ }^{17}$.

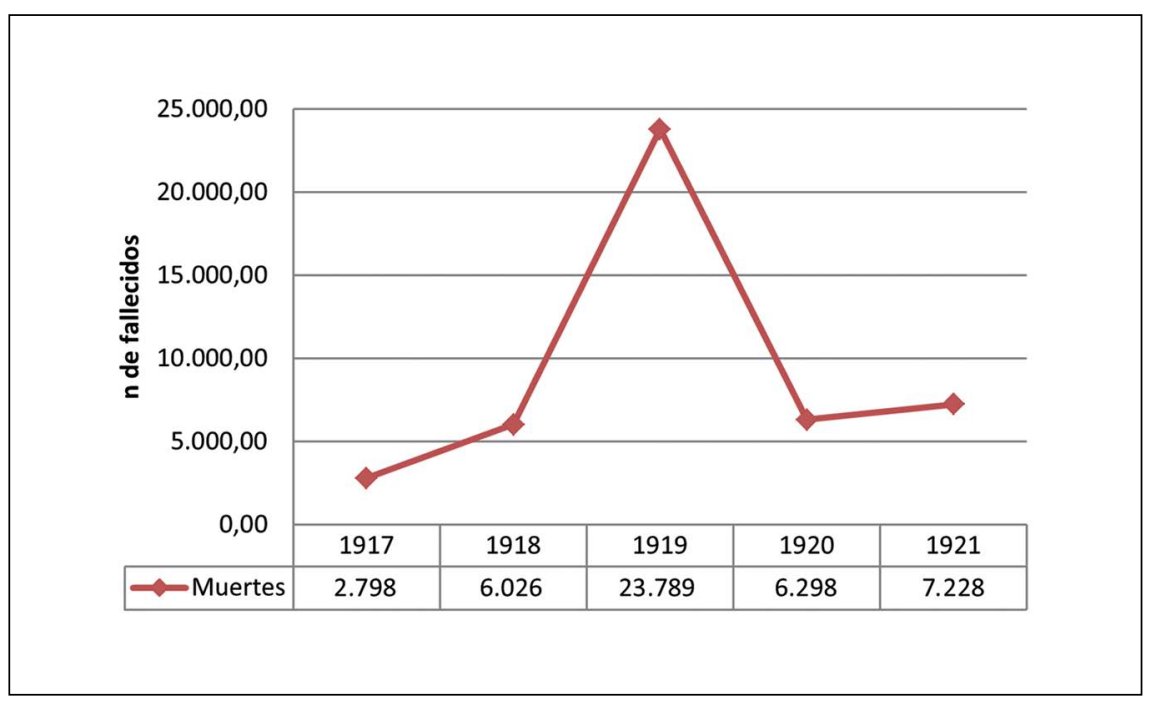

Figura 1. Muertes por influenza española en Chile, 1917-1921 (Anuario Estadístico de la República de Chile, años 1918, 1919, 1920 y 1921. Es importante hacer presente que del total de muertes contabilizadas entre 1918 y 1921 , solamente 2.676 fueron certificadas por médicos, mientras que el resto de ellas, 37.437, fueron registradas por "testigos." Bajo esta figura se comprendía desde practicantes hasta funcionarios públicos ligados a los hospitales o el Registro Civil, hecho que nos introduce en uno de los debates que arrastró por décadas la salubridad moderna y que se refiere a la fiabilidad de las estadísticas médicas. Por ello, es pertinente valorar con cierta reserva la cifra que 40.113 muertos). 
Apostar a la amplia diseminación de la enfermedad en la población en búsqueda de protección de rebaño, ha sido una apuesta adoptada por pocos países (Inglaterra, que desistió tempranamente y Suecia $)^{18,19}$, por las consideraciones anteriores y por la baja estimación de la población afectada en base a evaluaciones serológicas realizadas en Islandia y España ${ }^{20,21}$.

Preocupa haber desatendido la importancia de intervenciones preventivas estructurales en la salud de los chilenos, muchas de ellas mencionadas y abordadas por nuestra Sociedad en su quehacer cientifico. La alta prevalencia en la población chilena de enfermedades crónicas y de sus principales factores de riesgo (tabaco, consumo de alcohol, entre otros), matizadas por gradientes socioeconómicas inversas y cobertura insuficiente de programas de atención, han generado situaciones propicias que pueden explicar -en forma retrospectiva- los alcances que alcanzará esta pandemia en la sociedad chilena ${ }^{22}$. Entre las comorbilidades relevantes, EPOC, asma bronquial, pacientes con cáncer pulmonar en tratamiento, enfermedades intersticiales y tabaquismo, se cuentan entre las condiciones con mayor riesgo de evolución hacia formas más severas de COVID-1923.

La fragilidad de los principales determinantes sociales en salud, reiteradamente mencionados y conocidos en nuestro medio y cuyos efectos si que pueden hoy comprenderse, ha quedado en evidencia en esta circunstancia. Precisamente son los grupos de población con debilidades manifiestas en la expresión de estos determinantes los que son afectados con mayor intensidad.

Para la medicina respiratoria, ha constituido un desafio importante disponer de todas sus capacidades para integrar una fuerza de tarea nacional, público-privada, para enfrentar este desafio. Más aún, cuando ha debido enfrentar a un enemigo cuya historia natural esta aun en pleno desarrollo, y que presenta aspectos diagnósticos y clínicos complejos y de dificil interpretación tanto en niños como en adultos (alteraciones severas de la coagulación, síndrome hiper-inflamatorio sistémico) ${ }^{24}$.

La expectativa de disponer de una vacuna eficaz, aun cuando se vislumbra hoy más cercana de lo esperable, debe considerar que su disponibilidad efectiva dependerá de factores logísticos de su producción y distribución, de costos, presiones y circunstancias políticas y comerciales, muchas veces gravitantes cuando productos y dispositivos se transforman en un bien por todos requeridos.

Frente a estos desafios del presente, la Sociedad Chilena de Enfermedades deberá redoblar sus esfuerzos en el futuro muy cercano, poniendo hincapié en el fortalecimiento de la cobertura de inmunizaciones, control del consumo de tabaco, control de la tuberculosis, el manejo comprehensivo de la Enfermedad Pulmonar Obstructiva Crónica, del cáncer pulmonar, asma bronquial, infecciones respiratorias agudas de niños y adultos, enfermedades de origen laboral, y patologías de menor frecuencia, pero crecientes en su tendencia e importancia en nuestro medio como son las enfermedades intersticiales del pulmón.

Ponemos en alerta la urgente necesidad de reconstituir a la brevedad, toda la capacidad de atención $y$ de cuidados de aquellos pacientes portadores de enfermedades respiratorias crónicas regularmente controlados en al ámbito ambulatorio en nuestro sistema de salud. Ellos, al igual que los millones de personas portadoras de enfermedades crónicas, han estado confinados y distanciados de los cuidados habituales. De no mediar una acción proactiva de nuestra parte, es factible esperar descompensaciones, hospitalizaciones y muertes evitables.

Como consideraciones finales, surge en primer término, el imperativo ético de mantener una actitud crítica y reflexiva sobre la situación de salud y las circunstancias que la determinan. Siendo Chile un país que se encuentra en una fase avanzada de la transición epidemiológica ${ }^{25}$, por mucho tiempo descansó en la tranquilidad de dejar en el pasado amenazas propias de las etapas anteriores de la transición, propias del subdesarrollo.

Una mirada crítica a esa visión apela a la necesidad de evaluar los nuevos riesgos en los que viven las sociedades contemporáneas, entre los cuales el descuido por el medio ambiente, de las especies animales, la inmediatez en movilidad de personas y bienes y las formas de vida en grandes urbes, propician la reemergencia de enfermedades y pandemias originadas por nuevos microorganismos ${ }^{26}$. 
Finalmente y recurriendo a lo afirmado por el historiador francés Emmanuel Le Roy Ladurie $e^{10,27}$ quien afirma que las situaciones de pandemia corresponden a "la unificación del mundo por la enfermedad", por la interrelación entre formas modernas de vida y su interactuación con la naturaleza propiciando un "mercado común" de microorganismos, es esperanzador también confiar en que la reacción del mundo entero conduzca, unificadamente, a formas de vida más solidarias y centradas en el bienestar de personas y comunidades.

\section{Dr. Gonzalo Valdivia C. ${ }^{1}$ \\ ${ }^{1}$ Profesor Titular, Departamento de Salud Pública, Facultad de Medicina, Pontificia Universidad Católica de Chile. Miembro de la Comisión Cientifica Sociedad Chilena de Enfermedades Respiratorias. Email:valdivia@med.puc.cl}

\section{Bibliografía}

1.- Novel Coronavirus (2019-nCoV) situation reports. [citado el 31 de mayo de 2020]. Disponible en https://www.who.int/docs/default-source/coronaviruse/situation-reports/20200121-sitrep-1-2019-ncov. pdf?sfvrsn=20a99c10_4.

2.- Wuhan seafood market pneumonia virus isolate WuhanHu-1, complete genome. 23 de enero de 2020 [citado el 31 de mayo de 2020]; Disponible en: http://www.ncbi. nlm.nih.gov/nuccore/MN908947.3.

3.- WU F, ZHAO S, YU B, CHEN Y. A new coronavirus associated with human respiratory disease in China. Nature 2020; 579 (7798): 1-8. doi:10.1038/s41586-0202008-3.

4.- PAUles CI, MARSTON HD, FAUCI AS. Coronavirus infections-more than just the common cold [published January 23, 2020].JAMA. doi:10.1001/ jama.2020.0757.

5.- LI Q, GUAN X, WU P, WANG X, ZHOU L,TONG $\mathrm{Y}$, et al. Early transmission dynamics in Wuhan, China, of novel coronavirus-infected pneumonia. N Engl J Med 2020; 382: 1199-207. doi:10.1056/NEJMoa2001316.

6.- WHO; Coronavirus disease (COVID-19) Situation Report-131, 30 May 2020. https://www.who.int/docs/ default-source/coronaviruse/situation-reports/20200530covid-19-sitrep-131.pdf?sfvrsn=d31ba4b3_2.

7.- MINSAL. Ministerio de Ciencias: Informe epidemiológico 31 de mayo de 2020. Disponible en: https://www. gob.cl/coronavirus/cifrasoficiales/\#datos).

8.- CONGRESO DE CHILE. Ley núm. 3.385 22-JUN1918. Disponible desde la Biblioteca del Congreso Nacional, Chile: Consultada el 31 de mayo de 2020. https://www.leychile.cl/Navegar?idNorma=169255\&i dParte $=$ \&idVersion $=1918-06-22$.

9.- LAVAL RE. Chile 1918: Las dos epidemias. Rev Chilena Infectol 2003; 20 (Supl): 133-5.

10.- LÓPEZ M, BELTRÁN M. Chile entre pandemias: la influenza de 1918, globalización y la nueva medicina. Rev Chilena Infectol 2013; 30: 206-15.
11.- WEBBY RJ, WEBSTER RG. 2003. Are we ready for pandemic influenza? Science 302: 1519-22.

12.- ORGANIZACIÓN MUNDIAL DE LA SALUD. Reglamento Sanitario Internacional (RSI). Ginebra: OMS; 2005. Disponible en: http://www.who.int/csr/ihr/ es/index.html.

13.- OECD Policy Responses to Coronavirus (COVID-19). Beyond containment: Health systems responses to COVID-19 in the OECD. OECD, Paris, France. Update April 16 2020. Consultado el 20 de mayo de 2020. Disponible en: https://read.oecd-ilibrary.org/ view/?ref=119_119689-ud5comtf84\&title=Beyond Containment:Health_systems_responses_to_COVID-19 in the OECD.

14.- MINSAL, Informe epidemiológico $\mathrm{N}^{\circ} 20$. Enfermedad por SARS-Cov2 (COVID-19). Chile, 26 de mayo de 2010. Departamento de Epidemiología.

15.- WHO. Laboratory testing strategy recommendations for COVID-19. Interim guidance 21 March 2020.

16.- WÖLFEL R, CORMAN V M, GUGGEMOS W, SEILMAIER M, ZOORGE S, MÜLLER MA, et al. Virological assessment of hospitalized patients with COVID-2019. Nature 2020; 581: 465-9. https://doi. org/10.1038/s41586-020-2196-x.

17.- LIU Y, GAYLE AA, WILDER-SMITH A, ROCKLOV J. The reproductive number of COVID-19 is higher compared to SARS coronavirus. J Travel Med 2020. Disponible en: https://doi.org/10.1093/jtm/ taaa021.

18.- HUNTER DJ. Covid-19 and the Stiff Upper Lip The Pandemic Response in the United Kingdom. N Engl J Med 2020; 10.1056/NEJMp2005755. Disponible en: https://www.nejm.org/doi/pdf/10.1056/ NEJMp2005755?articleTools=true

19.- ANDERSEN AL, HANSEN ET, JOHANNESEN N, SHERDIAN A. Pandemic, Shutdown and Consumer Spending: Lessons from Scandinavian Policy Responses to COVID-19. 2020; arXiv: 2005.04630. [Econ.GN], Publicado 'online' 10 de mayo de 2020.

20.- GUDBJARTSSON DF, HELGASON A, JONSSON H, MAGNUSSON OT, MELSTED P, NORDDAHL 
GL, et al. Spread of SARS-CoV-2 in the Icelandic population. New Engl J Med (2020).

21.- Antibody study shows just 5\% of Spaniards have contracted the coronavirus. Diario EL País, España. 14 mayo 2010. Consultado el 31 de mayo de 2020. Disponible en: https://english.elpais.com/society/2020-05-14/ antibody-study-shows-just-5-of-spaniards-have-contracted-the-coronavirus.html

22.- MINSAL, Departamento de Epidemiología: Encuestas Nacionales de Salud 2003, 2009-10, 2016-17. Disponible en: http://epi.minsal.cl/resultados-encuestas/

23.- WILLIAMSON E, WALKER AJ. BHASKARAN KJ, BACON S, BATES S, MORTON CE, et al. The OpenSAFELY Collaborative. OpenSAFELY: factors associated with COVID-19-related hospital death in the linked electronic health records of 17 million adult NHS patients. medRxiv. 2020. doi: 10.1101/2020.05.06.2009 2999. publicado 'online' 7 de mayo de 2020 (preprint).

24.- WHO. Clinical management of COVID19. Interim guide. May 27 2020. Disponible en : https://www.who.int/ publications-detail/clinical-management-of-covid-19

25.- OMRAN AR. The epidemiologic transition: a theory of the epidemiology of population change. Milbank Mem Fund Q 1971; 49: 509-83.

26.- MCKEOWN RE. The epidemiologic transition: changing patterns of mortality and population dynamics. Am J Lifestyle Med 2009; 3: 19S.

27.- LE ROY LADURIE E. Un concepto: la unificación microbiana del mundo (siglos XIV-XVII). Historias, núm. 21, INAH, México, 1989, pp. 33-69. 